Çukurova Üniversitesi Mühendislik Mimarlık Fakültesi Dergisi, 30(1), 175-182ss., Haziran 2015

Çukurova University Journal of the Faculty of Engineering and Architecture, 30(1), pp. 175-182, June 2015

\title{
Dalgaboyu Bölümlemeli Çoğullama (DBÇ) Üzerinde Optik Çoğuşma Anahtarlama (OÇA) ve Çoğa Gönderim
}

\author{
Pinar KIRCI ${ }^{* 1}$, Halim ZAİM ${ }^{2}$ \\ ${ }^{1}$ İstanbul Üniversitesi, Mühendislik Fakültesi, Bilgisayar Mühendisliği Bölümü, İstanbul \\ ${ }^{2}$ İstanbul Ticaret Üniversitesi, Mühendislik Fakültesi, Bilgisayar Mühendisliği Bölümü, İstanbul
}

Geliş tarihi: 15.04 .2015

Kabul tarihi: 24.06 .2015

\section{Özet}

Son yıllarda internet kullanımının katlanarak artması, kullanıcılara sunulan internet uygulamalarındaki çeşitlilik ve bunların hızlı gelişimi, çok büyük oranlarda bantgenişliği talebini ortaya çıkarmıştır. Özellikle bire-çok bağıntı ya da çoktan-çok bağıntı iletişimi yapısında olan çoğa gönderim uygulamalarını temel alan yüksek bantgenişliği gerektiren uygulamalardan video konferans, uzaktan interaktif eğitim gibi örnekler optik ağlarda Dalgaboyu Bölümlemeli Çoğullama-DBÇ (Wavelength Division MultiplexingWDM) teknolojisi sayesinde kullanıcılara kolaylıkla ulaştırılmaktadır. Bu çalışmada Optik Çoğuşma Anahtarlama (Optical Burst Switching-OBS) ağlarda çoğa gönderimi sağlayabilmek için Önceden Hesaplanan Yol Çoğa Gönderim (Precalculated Path Multicast-PPM) isimli yeni bir protokol sunulmuştur. Protokol yapısı ve işleyişi durum diyagramları kullanılarak açıklanmıştır.

Anahtar Kelimeler: Optik çoğuşma anahtarlama, OÇA, Optik ağlar, Dalgaboyu bölümlemeli çoğullama

\section{Optical Burst Switching (OBS) and Multicasting over Wavelength Division Multiplexing (WDM}

\begin{abstract}
The great increase of internet utilization, the variety and quick developments of internet applications that are proposed to the users, reveals the demand of great amounts of bandwidth requirment. Especially, one to many or many to many transmission type, multicast based and high bandwidth needed applications like video conference and distance interactive education are transmitted to the users easily by the Wavelength Division Multiplexing (WDM) technology in OBS (Optical Burst Switching) networks. In this study, to provide multicasting in OBS networks a new protocol which is named as Precalculated Path Multicast (PPM) is presented. Protocol architecture and mechanism is explained by state diagrams.
\end{abstract}

Keywords: Optical burst switching, OBS, Optical networks, Wavelength division multiplexin

\footnotetext{
* Yazışmaların yapılacağı yazar: Pınar Kırcı, İ.Ü., Mühendislik Fakültesi, Bilgisayar Mühendisliği Bölümü, İstanbul.pkirci@istanbul.edu.tr
} 


\section{GíRiş}

Internetteki trafik talebi her geçen gün çı̆̆ gibi büyüdüğünden, WDM optik ağ teknolojisindeki dikkat çekici ilerlemeler, optik interneti daha da aranılır kılmış böylece WDM, ağ omurgaları için doğal bir seçim olmuştur. WDM teknolojisi, binlerce düğümden oluşan çok büyük geniş alan ağları oluşturma imkanı sağlar. $\mathrm{Bu}$ yüzden, araştırmacılar WDM tabanlı optik ağların gelecekte devasa trafik iletişimini sağlayacak geniş bant ağların omurgası olacağını düşünmektedirler. Son zamanlarda WDM üzerinde IP (Internet Protocol) ağlar ya da optik internet oldukça dikkat çekmektedir. Bu arada çoğa gönderim yapısı da gittikçe popüler olmaktadır. Çoğa gönderimin en önemli faydaları, iletim masrafinı (overhead) ve verinin alınmasındaki gecikme zamanını azaltmasıdır $[1,2]$.

Her bağlantı isteğinin sadece bir dalgaboyu $(\lambda)$ olduğunu farzedersek, her fiber için en fazla bağlantı sayısı w olur. Fiberde $\lambda_{1}, \lambda_{2, \ldots .} \lambda_{\mathrm{w}}$ varsa ve eğer bir bağlantı isteği Mbps oranlarındaysa, saniyede gigabitlerin katları kadar dalgaboyu tahsis edilir. $\mathrm{Bu}$ durum veri iletiminde fiber üzerinde çok büyük bantgenişliği kaybına sebep olur. Tam optik iletim yolu olan 1 şı yolunda (lightpath), dalgaboyu yönlendiricileri veri yolunu Elektrikselden Optiğe (Electrical to Optical-E/O) ve Optikten Elektriksele (Optical to Electrical$\mathrm{O} / \mathrm{E})$ dönüşüm olmaksızın tam optik olarak yapılandırır. Dalgaboyu yönlendiricilerinin görevi, dalgaboylarını çoğullamak/çoğullamalarını çözmektir. Bu sayede gelen portlardaki dalga boyları, istenilen çıkış portlarına yönlendirilebilmektedir. Tam optik anahtarlamanın amacı elektronik anahtarlama yerine veriyi optik olarak anahtarlayabilmektir, böylece optoelektronik yapılara da gerek kalmayacak ve maliyet de düşecektir ayrıca protokol saydamlığı (transparency) sağlanacak ve güç tüketimi de düşecektir $[3,4]$.

WDM üzerinde IP ağlarda çoğa gönderim, birden fazla WDM teke gönderimi ile yada WDM çoğa gönderimi ile yapılabilir. Ancak son zamanlarda bir işaretin, kaynak kenar yönlendiriciden birçok varış noktasına Optik Elektriksel Optik (Optical
Electrical Optical-O-E-O) dönüșüme uğramadan gönderilmesi yani WDM çoğa gönderimi üzerine yoğunlaşılmakta ve bu konuda çalışmalar yapılmaktadır. Bantgenişliği, gecikme süresi daha etkin çoğa gönderim ağaçları WDM katmanında rahatlıkla oluşturulabilir. Ayrıca yapısında 1 şık ayrıştırma (light splitting) özelliği olan optik anahtarlar ile 1şık ayrıştırma yapmak IP datagramları eletronik olarak kopyalamaktan daha etkilidir. Sonuç olarak, WDM katmandaki çoğa gönderim,veri iletimi için daha yüksek derecede veri saydamlığı (bit oranı ve kod formatı anlamında) sağlar [5].

Çalışmamızın 1. bölümünde dalgaboyu bölümlemeli çoğullama yapısı özetlenmiştir. 2. bölümde dalgaboyu bölümlemeli çoğullama (DBÇ) ağlar ve anahtarlama teknolojileri incelenmiştir. 3. bölümde optik çoğuşma anahtarlama ayrıntılı bir şekilde anlatılmıştır. Bölüm 4 içinde çoğa gönderim yapısı ayrıntılı bir şekilde açıklanmıştır. Bölüm 5'de ise üzerinde çalışılan ağ yapısı açıklanmış ve elde edilen sonuçlar grafikler ile sunulmuştur.

\section{DALGABOYU BÖLÜMLEMELI ÇOĞULLAMA (DBÇ) AĞLAR VE ANAHTARLAMA ÇEŞITLERI}

Günümüzde WDM ağlar üç ana alt başlık altında incelenmektedir. Bunlar Yönlendirme (Wavelength Routing-Dalgaboyu-WR), Optik Paket Anahtarlama (Optical Packet SwitchingOPS) ve Optik Çoğuşma Anahtarlama (Optical Burst Switching-OBS). Dalga boyu yönlendirmeli ağlar, devre anahtarlamalı ăg yapısına benzer bir yapıdadır yani bir kaynaktan bir varış noktasına veri gönderebilmek için 1 şı yolu (lighpath) kurulması gerekir ki bu durumda dinamik trafik yapısına uygun değildir çünkü ışık yolu üzerindeki bütün bant genişliği söz konusu kaynak ve varış noktası tarafindan rezerve edilir ve bu çiftin aralarında trafik akışı olmasa bile diğerleri tarafından kullanılamaz. Dalgaboyu Yönlendirme, yüksek bant genişliği gerektiren video uygulamalarından Yüksek Çözünürlükte Televizyon (High Definition Television-HDTV) dağıtımları gibi çoğa gönderim uygulamaları için 
uygun bir çözümdür. Paket yönlendirmeli ağlardaki trafik, yönlendiricilerde elektronik olarak anahtarlanır. $\mathrm{Bu}$ yöntem oldukça esnek ve uygulanabilir bir yöntem olarak bilinmektedir. Bu elektriksel paket yönlendiriciler, oldukça masraflı olan optik-elektrik-optik dönüşüm gereksinimi nedeniyle optik ağlar için çok da uygun değildir.

Optik paket yönlendirmeli ağlarda, optik-elektrikoptik dönüşümünü ortadan kaldırabilmek için optik paket anahtarlama yöntemi geliştirilmiştir. Optik paket anahtarlamada, paketler anahtarlama düğümlerine düzensiz bir şekilde gelirler ve aynı kaynağı aynı anda kullanmak isteyebilirler böyle bir durumda da tamponlama gerekir ki optik tamponlama hala büyük problemlerden biridir. OPS ağ, daha çok elektronik paket anahtarlamalı ağlara benzer bu yüzden de dinamik trafik yapısına daha kolay uyum sağlayabilir fakat anahtarlarda optik tamponlara ihtiyaç duyduğundan uygulaması zordur ancak bu durum günümüz teknolojisinde pahalı fiber gecikme hatları kullanılarak çözümlenebilir.

OBS ise ağda trafik olmadığında bant genişliğini boşuna meşgul etmez ve anahtarlarında geniş optik tamponlara ihtiyaç duymaz. WDM çoğa gönderimde, optik çoğuşma anahtarlamalı trafik, dalga boyu yönlendirmeli trafikten daha etkindir [6-8].

Tamponsuz ve kayıpsı OCS ( $\lambda$-anahtarlamalı) Optik Devre Anahtarlama (Optical Circuit Switching) ağlarda ise uçtan uca (end to end) yapıda 1şık yolları yani dalga boyu kanalları kurulur ve her 1 şı yolu da izlediği tüm bağlar boyunca olan aynı dalga boyunun tüm $\lambda$-bant genişliğini kapsamak zorundadır. Bu durum, dalga boyu süreklilik durumudur [9].

\section{OPTİK ÇOĞUŞMA ANAHTARLAMA VE PAKET ILETIMI}

Aynı düğüme gitmek isteyen paketlerin daha büyük optik paketler halinde yani çoğuşmalar halinde iletilmesine OBS denir. OBS yapısında, ağ giriş düğümünde, gelen IP paketleri optik çoğuşmalar oluşturmak için sanal kuyruklarda (her varış noktasına bir tane olmak üzere) toplanırlar. Sonrasinda bir kontrol paketi üretilir ve veriden kararlaştırılmış bir offset (gecikme zamanı) zamanı öncesi yol üzerindeki uygun kaynakları rezerve etmesi ve uygun bir zaman-slotu ayırması için optik ağda kontrol kanalı üzerinden Şekil 1'de gösterildiği gibi iletilir [10].

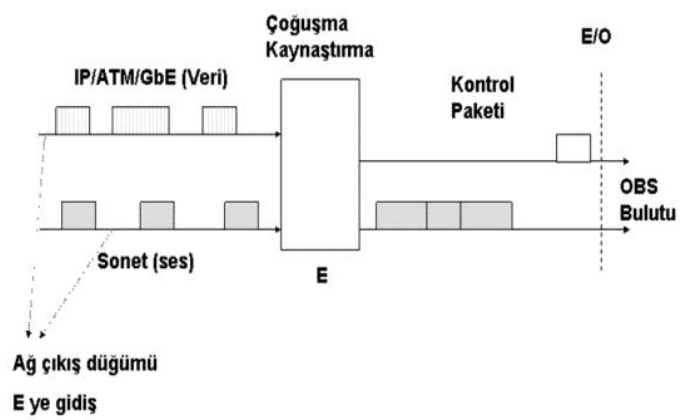

Şekil 1. Bir giriş düğümünde çoğuşma kaynaştırması

Her OBS düğümünde kontrol paketini işlemek belli bir zaman alır. Kontrol paketi her zaman ardından gelen veri çoğuşmasının önünde olur. Kontrol paketi ile veri çoğuşmasının birçok OBS anahtar düğümünden geçtiği andaki durumları ve aralarındaki ofset zaman kullanımı Şekil 2'de gösterilmiştir.

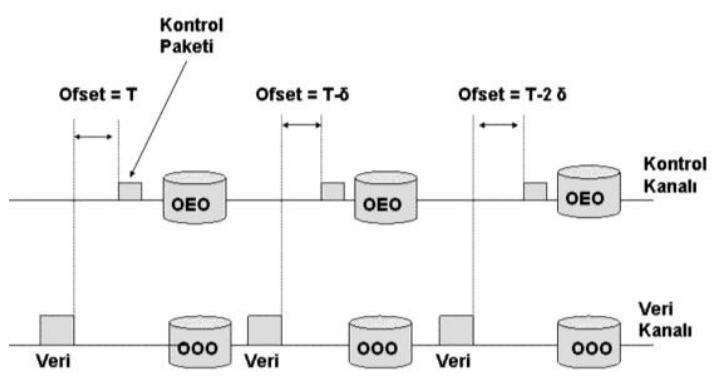

Şekil 2. OBS ağından çoğuşma iletimi

Şekil 2'de gösterildiği üzere kontrol paketi ve veri farklı zamanlarda farklı kanallardan gönderilir.

Son olarak Şekil 3'de gösterildiği gibi ağ çıkış düğümünde çoğuşmalar ayrılır. OBS'de kontrol paketi, yönlendirme bilgisinin yanında çoğuşma uzunluğu ve ofset zamanı bilgilerini de taşır. $\mathrm{Bu}$ 
sayede IP/SONET/WDM yaklaşımları ile karşılaştırıldı̆̆ında OBS, ă̆ kontrolünü ve donanım dizaynını performans kaybı olmadan büyük ölçüde basitleştirebilir. OBS yapısında bir veri kanalı sadece çoğuşma gelişinden gidişine kadar rezerve edilir ve bu durum OBS'in en yüksek kaynak etkinliğine ulaşmasını sağlar. OBS, OPS ve WR teknolojilerinin avantajlarını kullanır ve WDM'in performansını geliştirir $[11,12]$.

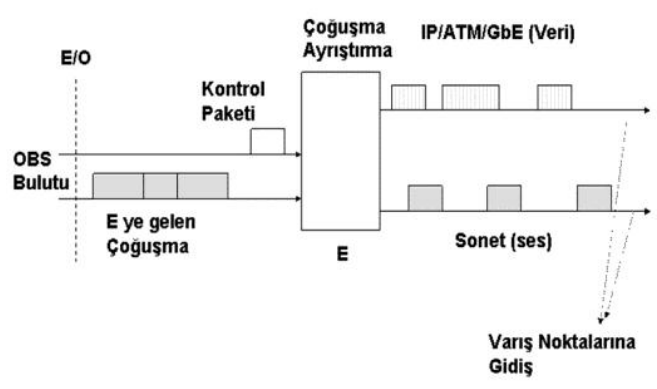

Şekil 3. Ağ çıkış düğümü

Son olarak Şekil 3'de gösterildiği gibi ağ çıkış düğümünde çoğuşmalar ayrılır. OBS'de kontrol paketi, yönlendirme bilgisinin yanında çoğuşma uzunluğu ve ofset zamanı bilgilerini de taşır. $\mathrm{Bu}$ sayede IP/SONET/WDM yaklaşımları ile karşılaştırıldığında OBS, ağ kontrolünü ve donanım dizaynını performans kaybı olmadan büyük ölçüde basitleştirebilir. OBS yapısında bir veri kanalı sadece çoğuşma gelişinden gidişine kadar rezerve edilir ve bu durum OBS'in en yüksek kaynak etkinliğine ulaşmasını sağlar. OBS, OPS ve WR teknolojilerinin avantajlarını kullanır ve WDM'in performansını geliştirir $[11,12]$.

Bir OBS ağı, kenar düğüm denilen uç aletlerden oluşur. Kenar düğümler, çoğuşmaların hem ileticileri olarak hem de alıciları olarak çalışabilirler. Bu aletler, IP, ATM ve Frame Relay (Çerçeve Aktarıcı) gibi birçok elektronik paket anahtarlamalı ağlara bağlıdır ve bir yada birden fazla OBS arayüzüne sahiptir. Her kenar düğümü, aralarında bir mesh (Çokgen Bağlantılı) ağ ile bağlı bir yada birden fazla çekirdek OBS düğümüne bağlıdır. Her çekirdek düğüm, tamponsuz bir Optik Statik Anahtardır (Optical
Cross Connect-OXC). Bu da demek oluyor ki çoğuşma varış noktasına doğru yol boyunca optik olarak iletilmektedir. Bir çok çoğuşma aynı fiber üzerinden art arta iletilebilir çünkü her fiber W tane dalgaboyu taşır.

OBS ağının en önemli özelliği, veri ve kontrol alanlarının ayrılmış olmasıdır. Paketlerin her kaynak düğümde alınması ve veri çoğuşmalarına dönüştürülmesi elektronik bölgede olur. $\mathrm{Bu}$ çoğuşmalar, optik bölgede bir yada birkaç çekirdek düğüm üzerinden taşınırlar, tekrar elektronik bölgeye dönüştürülecekleri varış kenar düğümlere iletilirler ve ilgili veri varış noktalarına iletilmek için ilk baştaki veri paketi hallerine ayrılırlar. Bir çoğuşmayı iletebilmek için tamponsuz optik ağ boyunca bir bağlantı kurulması gerekir. Bu bağlantı, kaynak adresi, varış adresi ve çoğuşmanın sürekliliğini içeren bir kontrol paketi gönderilmesi ile kurulur. Bu kontrol paketi, optik olarak bant içi (in-band), bant dışı (out-of-band) yada elektronik olarak bant dişı iletilir ve her çekirdek düğüm tarafından elektronik olarak işlenir.

OBS, veri için optik anahtarlamayı, kontrol paketleri için ise elektronik anahtarlamayı kullanır. Çoğuşma anahtarlama, iyi bir istatistiksel çoklama performansı sağlayabilmek için ya büyük oranda optik tamponlara yada optik dalgaboyu dönüştürücülere ihtiyaç duyar. Günümüzde optik tampon olarak gecikme hatları kullanılmaktadır ancak çoğuşma anahtarlamada dalgaboyu dönüştürücüler kullanılarak tamponlama ihtiyacı azaltılmaya çalışılmaktadır [13].

\section{4. ÇOĞA GÖNDERIM (MULTICAST) YAPISI}

Verinin bir bilgisayar ağında bireysel alıcılara değil de bir grup alıcıya gönderilmesi çoğa gönderim mantığıdır. Ağda, bir çoğa gönderim oturumunu etkili bir biçimde desteklemek için oturum bilgisinin iletileceği bir çoğa gönderim ağacının kurulması gerekir. Bu çoğa gönderim ağaçlarını hesaplayan algoritmalara çoğa göderim yönlendirme algoritmaları denir. Uygun bir çoğa gönderim ağacı bulma NP-Tam'dır 
(NP-Complete). Çoğa gönderim servisi multimedya uygulamalarını destekleyen bilgisayar ağları için çok gereklidir [14,15]. Günümüzde, Video Konferans, Ismarlama Video (Video on Demand-VOD), Paralı Televizyon Yayını (Pay per view-PPV), IP Televizyon (IPTV) en çok bilinen çoğa gönderim uygulamalarındandır.

WDM katmanında çoğa gönderimi desteklemek için 1şık-ağaç (Optical Light-Tree) konsepti sunulmuştur. $\mathrm{Bu}$ yaklaşım 1 şık yolun noktadanbirçok noktaya olacak şekilde geliştirilmiş halidir. Bir 1şık ağacın düğümlerini dallandırmak için Güç Üleştirici (Power Splitter) kullanılır. Güç üleştirici çok pahalı olduğundan, ağın düğ̈̈mlerinin sadece bir bölümünde kullanılır. Bu tip ağlar SeyrekDağılan (Sparse-Splitting) ağlar olarak adlandırılır [16].

İnternet üzerindeki çoğa gönderim iletimi iki yolla sağlanır, birincisi, Bölgesel Grup Yönetimi, ikincisi ise Global Çoğa Gönderim Yönlendirmesidir. Birinci yöntem, çoğa gönderim yönlendiricilerinin direk olarak bağlı oldukları ağlardaki grup üyelerinin varlıklarını öğrenmelerine izin verir. Bölgesel çoğa gönderim yönlendiricilerinin en önemli özelliği, gruptaki üyelerin varlık ve yokluklarını algılayabilme sürelerinin oldukça kısa olmasıdır. Bir düğümün bir gruba eklenmesi ile paket almaya başlaması arasındaki geçen zaman eklenme gecikmesi ve gruptan ayrilan son üye ile komşu çoğa gönderim yönlendiricisinin bu grupta hiç üye kalmadığını anlaması arasında geçen zamanda ayrılma gecikmesidir ve bu yönlendiriciler bu gecikmeleri grup katılımlarında mümkün olduğunca azaltmayı amaçlamaktadırlar. İkinci yöntem ise çoğa gönderim yönlendiricilerinin, internette gönderilen çoğa gönderim verilerinin, üzerinden iletileceği çoğa gönderim ağaçlarına karar verebilmek için veri değiş tokuşuna olanak tanır [17].

Çoğa gönderim ağacının nasıl oluşturulduğuna bağlı olarak, çoğa gönderim yönlendirme protokolleri iki alt başlıkta toplanmıştır.

Kaynak-temelli

Merkez-temelli
Kaynak temelli yaklaşımda, kaynak düğümden köklendirilen bir ağaç oluşturulur ve bu ağaç çoğa gönderim grubundaki her üye ile bağlantılıdır. Merkezi kaynak düğümde olan veri paketleri, çoğa gönderim ağacının bağları üzerinden bütün varış düğümlerine gönderilir. DVMRP (Distance Vector Multicast Routing Protocol- Uzaklık Vektör Çoğa Gönderim Yönlendirme Protokolü) [18], MOSPF (Multicast Open Shortest Path First- Çoğa Gönderim Açık En Kısa Yol İlk Protokolü) [19], PIM-DM (Protocol Independent Multicast Dense Mode-Protokol Bağımsız Çoğa Gönderim Yoğun Durum Protokolü) [19], EXPRESS (Explicitly Requested Single Source Multicast-Açıkça İstenen Tek Kaynak Çoğa Gönderim Protokolü) [20] kaynak temelli çoğa gönderim ağaç kategorisine girer.

Her grup için belirli bir düğüm, merkez ya da randevu noktas1 (rendezvous point-RP) olarak seçilir ve bu merkezden kök salan bir ağaç bütün grup üyelerini dolaşması amaciyla oluşturulur. CBT (Core Based Tree Protocol- Merkez Temelli Ağaç Protokolü) [21], PIM-SM (Protocol Independent Multicast Sparse Mode-Protokol Bağımsız Çoğa Gönderim Seyrek Durum) [22] ve SM (Simple Multicast - Basit Çoğa Gönderim) [21] merkez temelli ağaçlardır.

\section{AĞ YAPISI VE SONUÇLAR}

Bu makale çalışmasında OBS ağlar üzerinde çoğa gönderim yapısı ele alınmış ve WDM üzerinde OBS kullanarak çoğa gönderim yapabilmek için yeni bir protokol tanımlanmıştır. Bu protokol yapısı, genişletilmiş sonlu durum makinesi (Extended finite state machine-EFSM) temel alınarak oluşturulmuştur. Protokolde, bir kaynak düğüm ve birçok istemci düğümleri arasındaki iletişim bir ağ giriş anahtar, birçok ara anahtar ve birden fazla kenar anahtar üzerinden sağlanmıştır. İletişim alanında protokol dizaynı için literatürde birçok yöntem sunulmuştur. Bunlar; kurallı (formal) dizayn yöntemi, durum geçiş modeli (state transition models-STM), programlama dili modeli (programming language model-PLM) ve hibrid modelleridir [23]. Hibrid modeli diğerleri ile karşılaştırıdığında en çok tercih edilen modeldir çünkü durum iletim ve programlama dili 
modellerinin avantajlı yanlarını bünyesinde barındırır. Çalışmamızda kullandığımız EFSM'de bir hibrid modeldir.

JET rezervasyon protokolü üzerinde teke gönderimde poisson üreteci ile elde edilen sonuçlar dikkate alınmış ve OBS ağ üzerinde teke gönderim uygulandığında elde edilen sonuçlara göre eklenme istek düşme oranları Şekil 4'de gösterilmiştir.

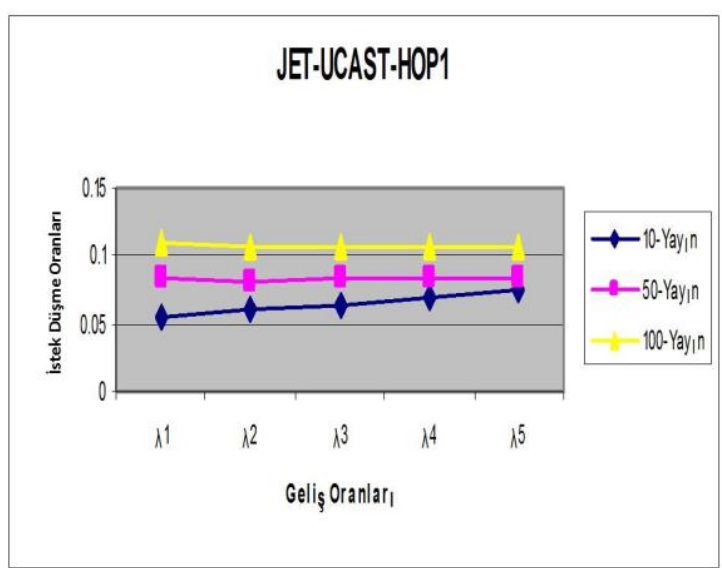

Şekil 4. Yayın sayısına göre $\lambda$ değerlerinin istek düşme oranlarına etkisi

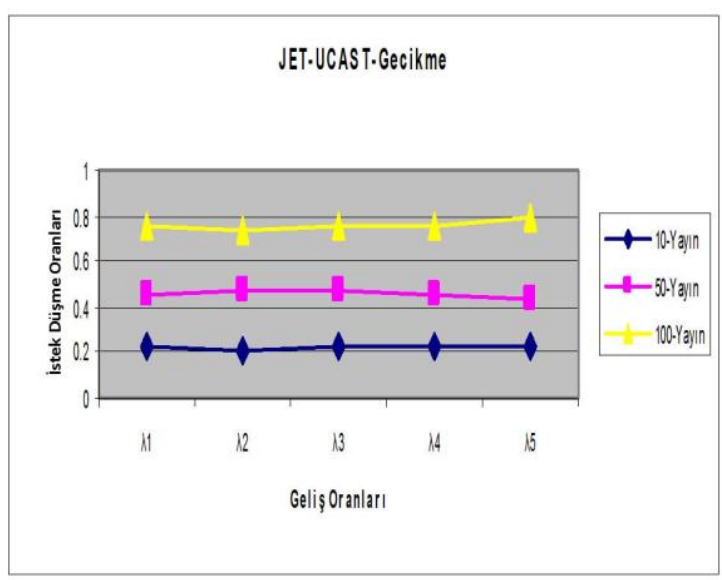

Şekil 5. Yayın sayısına göre isteklerin kaynağa varış gecikmeleri

Şekil 5'de istemciden gönderilen eklenme istek mesajlarının kaynağa varış gecikmeleri yayın sayısına ve trafik üretecine bağlı olarak gösterilmiştir.

JET rezervasyon protokolü üzerinde teke gönderimde selfsimilar üreteci ile elde edilen sonuçlar Şekil 6 ve Şekil 7'de gösterilmiştir.

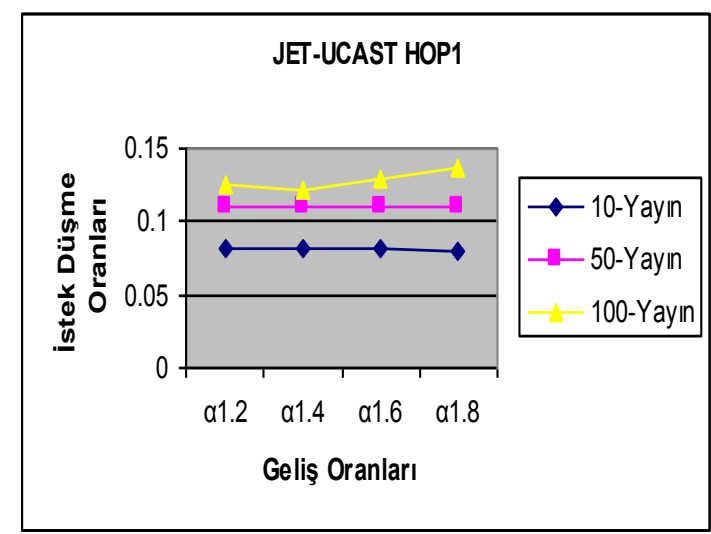

Şekil 6. Yayın sayısına göre $\alpha$ değerlerinin istek düşme oranlarına etkisi

Şekil 4 ve Şekil 6'da görüldüğü gibi OBS ă̆ üzerinde teke gönderim yapısında Selfsimilar trafik üreteci uygulandığında ve poisson trafik üreteci ile karşılaştırıldığında eklenme istek düşme oranları daha yüksek çıkmaktadır.

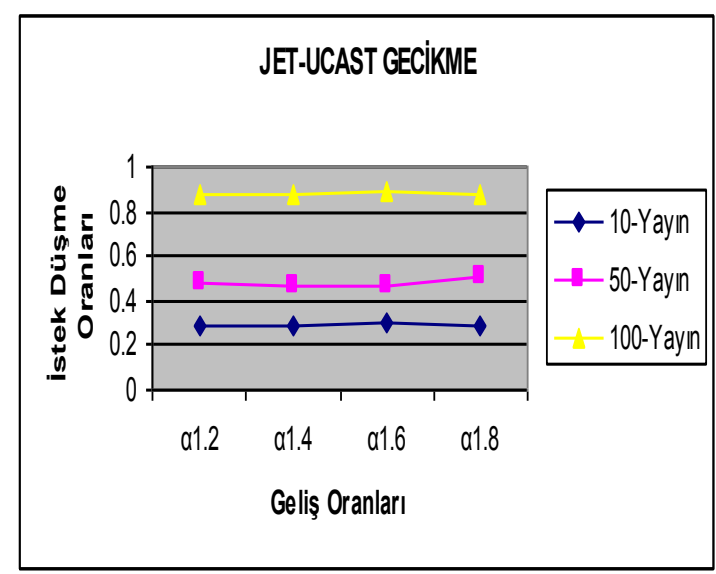

Şekil 7. Yayın sayısına göre isteklerin kaynağa varıș gecikmeleri

Şekil 7'de istemciden gönderilen eklenme istek mesajlarının kaynağa varış gecikmeleri yayın 
sayısına ve trafik üretecine bağlı olarak gösterilmiştir.

\section{SONUC}

Her geçen gün artan bantgenişliği talebi, iletim ağlarının en büyük problemidir. $\mathrm{Bu}$ ihtiyacı karşılayabilmek için OBS ağları sunulmuştur. OBS ağları, WDM ağlar üzerinde IP trafiğini desteklemek amaciyla anahtarlama teknolojisi olarak sunulmuştur. OBS yapısı üzerinde JET kanal rezervasyon protokolü en çok tercih edilen ve çalışılan kanal rezervasyon protokolüdür.

OBS ağ üzerinde teke gönderim uygulandığında elde edilen sonuçlara göre eklenme istek düşme oranları ve gecikme oranları ele alınmıştır. JET rezervasyon protokolü üzerinde teke gönderimde poisson ve selfsimilar üreteci ile elde edilen sonuçlar üzerine çalışılmış ve grafiklerle gösterilmiştir. Simulasyonlar, poisson trafik üretecinin farklı $\lambda$ ve selfsimilar trafik üretecinin farklı $\quad \alpha \quad$ değerlerinde JET üzerinde gerçekleştirilmiştir.

\section{KAYNAKLAR}

1. Jeong, M., Qiao, C., Xiong, Y., 2000a. ReliableWDM Multicast in OBS Networks, Opticomm 2000, 153-166p.

2. Wang, Y., Yang, Y., Multicasting 2002. In a Class of Multicast-Capable WDMNetworks, Journal of Lightwave Technolgy, Vol. 20, No.3, March.

3. Huei,Y. C., Keng, P.H., 2005. A Shared Time Slot Router Architecture for TDM Wavelength Optical WDM Networks, 1 4244-0000-7-05, IEEE.

4. Ramamirtham, J.,Turner, J., 2003. Time Sliced Optical Burst Switching, IEEE INFOCOM, 0-7803-7753-2.

5. Jeong, M., Qiao, C., Xiong, Y., Vadenhoute, M., 2000b. Evaluation of Multicast Schemes in Optical Burst Switched Networks-the Case with Dynamic Sessions, Proc. Spie, Vol. 4213, 187-197p.
6. Jeong, M., Qiao, C., Xiong, Y., 2000a. Reliable WDM Multicast in OBS Networks, Opticomm 2000, 153-166p.

7. Zhang, Z., Liu, L., Yang, Y., 2006. Slotted Optical Burst Switching (sOBS) Networks, 0-7695-2640-3-06,IEEE.

8. Zhang, X., Wei, J., 1999. On Fundemental Issues in IP over WDM Multicast, IEEE 1999 0-7803-5794-9/99.

9. Liew, S.Y., Chao, H.J., 2003. On Slotted WDM Switching in Bufferless All-Optical Networks, 11th Symposium on High Performance Interconnects (HOTI03), 0-7695-2012-X, IEEE.

10. Kantarci, B., Oktug, S.F., 2008. Loss RateBased Burst Assembly to Resolve Contention in Optical Burst Switching Networks, IET Commun., 2, 1, 137-143p.

11. Qiao, C., Chen, Y., Staley, J., 2003. The Potentials of Optical Burst Switching (OBS), Optical Fiber Communication Conference, OFC, Atlanta,Georgia.

12. Kantarci, B., Oktug, S.F., Atmaca, T., 2007. Performance of OBS Techniques Under SelfSimilar Traffic Based on Various Burst Assembly Techniques, Sciencedirect, Computer Communications 30, 315-327,

13. Mountrouidou, X., Perros, H., 2006. A Zero Burst Loss Architecture For Star OBS Networks, Net-Con 2006 (Part Of The IFIP World Computer Congress 2006), Sandiago, Chile, August 20-25.

14. Witmann, R., Zitterbart, M., 2001. Multicast Communication", Morgan Kauffman Publishers ISBN 3-920993-40-3.

15. Cormen, T.H., Leiserson, C.E., Rivest, R.L., Stein, C., 2001. Introduction to Algorithms, The MIT Pres ISBN- 0-262-03293-7.

16. Yang, D.N., Liao, W., 2003. Design of Light-Tree Based Logical Topologies For Multicast Streams In Wavelength Routed Optical Networks", IEEE 2003, 0-7803-77532-03.

17. Liao, W., Yang, D.N., 2004. Receiver-Initiated Group Membership Protocol (RGMP): A New Group Management Protocol for IP Multicasting, 0018-9316-2004 IEEE Transactions on Tümegönderiming, vol. 50, no.3. 
18. Ballardie, A., 1997. Core Based Trees (CBT) Multicast Routing Architecture, Internet Request for Comment 2201, September.

19. Wang, B., Hou, J.C., 2000. Multicast Routing and its Qos Extension Problems, Algorithms and Protocols, IEEE network, Vol.14, Issue.1, 22-36p.

20. Paul, P., Raghavan, S.V., 2002. Survey of Multicast Routing Algorithms And Protocols, Redefining Internet In The Context Of Pervasive Computing; Vol. I, Mumbai, Maharashtra, India, 902-926p, ISBN:1-891365-08-8.

21. Oliveira, C.A.S., Pardalos, P.M., 2005. A Survey of Combinatorial Optimization Problems in Multicast Routing, Computers and Operations Reserach Volume 32, Issue 8, August, 1953-1981p.

22. Estrin, D., Farinacci, D., Helmy, A., Thaler, D., Deering, S., Handley, M., Jacobson, V., Liu, C., Sharma, P., Wei, L., 1998. Protocol Independent Multicast-Sparse Mode (PIM-SM): Protocol Specification, Internet Request for Comment 2362, June.

23.Zaim, A.H., Baldine, I., Cassada, M., Rouskas, G.N., Perros, H. G., Stevenson, D., 2003. Jumpstart Just in Time Signaling Protocol a Formal Description Using Extended Finite State Machines, Society of Photo Optical Instrumentation Engineers, 42-2-568-585p, February. 